\title{
Metallurgical and Machinability Characteristics of Wrought and Selective Laser Melted Ti-6Al-4V
}

\author{
Manikandakumar Shunmugavel, Ashwin Polishetty, \\ Junior Nomani, Moshe Goldberg, and Guy Littlefair
} School of Engineering, Faculty of Science, Engineering and Built Environment, Deakin University,
Waurn Ponds, Geelong, VIC, Australia

Correspondence should be addressed to Manikandakumar Shunmugavel; mshunmug@deakin.edu.au

Received 13 June 2016; Revised 16 September 2016; Accepted 18 September 2016

Academic Editor: Sunghak Lee

Copyright (C) 2016 Manikandakumar Shunmugavel et al. This is an open access article distributed under the Creative Commons Attribution License, which permits unrestricted use, distribution, and reproduction in any medium, provided the original work is properly cited.

\begin{abstract}
This research work presents a machinability study between wrought grade titanium and selective laser melted (SLM) titanium Ti$6 \mathrm{Al}-4 \mathrm{~V}$ in a face turning operation, machined at cutting speeds between 60 and $180 \mathrm{~m} / \mathrm{min}$. Machinability characteristics such as tool wear, cutting forces, and machined surface quality were investigated. Coating delamination, adhesion, abrasion, attrition, and chipping wear mechanisms were dominant during machining of SLM Ti-6Al-4V. Maximum flank wear was found higher in machining SLM Ti-6Al-4V compared to wrought Ti-6Al-4V at all speeds. It was also found that high machining speeds lead to catastrophic failure of the cutting tool during machining of SLM Ti-6Al-4V. Cutting force was higher in machining SLM Ti-6Al-4V as compared to wrought Ti-6Al-4V for all cutting speeds due to its higher strength and hardness. Surface finish improved with the cutting speed despite the high tool wear observed at high machining speeds. Overall, machinability of SLM Ti-6Al-4V was found poor as compared to the wrought alloy.
\end{abstract}

\section{Introduction}

Titanium alloy Ti-6Al-4V is widely used in aerospace, automobile, marine, and biomedical industries because of its high strength to weight ratio, high corrosion resistance, and good biocompatibility [1]. Currently, wrought processing represents the state-of-the-art technology for producing titanium alloys with microstructure and mechanical properties necessary for critical applications. However wrought components are expensive for use in most applications, due to the multistep, energy intensive, thermomechanical processing routes used. Because of this, powder metallurgy and additive manufacturing have long been sought as a means to reduce production costs of $\mathrm{Ti}$ alloys, owing to additive manufacturing technologies near net shape capabilities and other advantageous features [2]. Additive manufacturing has gained attention among researchers and manufacturing industries because of its advantageous capabilities such as freedom of design, on-demand manufacturing, reduced raw material wastage, and low energy consumption [3]. In the last decade, several additive manufacturing techniques for processing of metals were proposed. Some of these techniques use wire as initial material (e.g., shaped metal deposition) and others use metallic powders (e.g., selective laser sintering (SLS), selective laser melting (SLM), and electron beam melting (EBM)) $[4,5]$. Each of these technologies has its own advantages and disadvantages. SLM is characterized by medium productivity and good repeatability and hence it is regarded as a suitable method for direct manufacturing of high quality parts with low to medium quantity [6]. Titanium parts fabricated using selective laser melting are being widely used in various fields such as biomedical implants and dental implants [7]. In addition, SLM fabricated parts also have huge potential in the aerospace and automobile industries [8]. It was also found that Ti-6Al-4V parts fabricated from SLM process (hereafter referred to as SLM Ti-6Al-4V) have higher yield strength, tensile strength, and hardness compared to wrought Ti-6Al-4V $[9,10]$. Murr et al. [11] reported high strength and hardness of SLM Ti-6Al-4V are mainly due to the martensite phase regimes present in its microstructure. 
As a consequence, the ductility in SLM Ti- $6 \mathrm{Al}-4 \mathrm{~V}$ is found significantly lower compared to wrought $\mathrm{Ti}-6 \mathrm{Al}-4 \mathrm{~V}$ aided by its peculiar microstructure and porosity [9].

In addition, the main drawbacks of SLM technology are the poor surface finish quality and its inability to fabricate complicated structures without using supporting frames/structures [12]. In order to overcome these drawbacks, postfinish machining of additive manufactured components is required to ensure product quality and tolerance limits. Machining of titanium alloys is cumbersome because the high cutting temperatures and high cutting pressures lead to rapid tool wear. Poor thermal conductivity of titanium alloys combined with their high chemical reactivity leads to high wear rate of cutting tools [13-15]. Only very few papers discussing the machinability of additive manufactured titanium alloys are available [16-22]. Oyelola et al. [16] investigated the machining behaviour and surface integrity of Ti-6Al-4V components produced by direct metal deposition additive manufacturing technology. Montevecchi et al. [17] investigated the cutting force behaviour of two additive manufacturing technologies such as laser deposition and wire arc additive manufacturing. Bordin et al. [20] compared the machinability of wrought and electron beam melted Ti-6Al$4 \mathrm{~V}$ during semifinish turning. Also recently, Bordin et al. [21] evaluated the tool wear mechanisms arising when semifinish turning EBM Ti-6Al-4V under dry and cryogenic conditions in an attempt to improve the machinability of additive manufactured components. Brinksmeier et al. [19] analysed the surface integrity of selective laser melting fabricated and subsequently machined Ti-6Al-4V samples. Bruschi et al. [18] analysed different lubrication/cooling strategies on surface integrity of machined electron beam melted samples to find the suitable option of environmental clean machining process of biomedical components. In addition, machine tool manufacturing companies such as DMG MORI integrate additive manufacturing and machining to improve the productivity and quality of the end components by utilising the advantages of both the technologies [23].

In light of current literature there has been little published work addressing the machinability characteristics of SLM Ti$6 \mathrm{Al}-4 \mathrm{~V}$. Clear understanding of machinability characteristics of SLM fabricated Ti- $6 \mathrm{Al}-4 \mathrm{~V}$ is required for improving the productivity of these materials. In view of this, the present study investigates machinability of additive manufactured Ti-6Al-4V and compares it with conventionally produced wrought Ti-6Al-4V during finish machining. Face turning trials using physical vapor deposition (PVD) coated tungsten carbide tools were carried out under dry cutting conditions at three cutting speeds between 60 and $180 \mathrm{~m} / \mathrm{min}$. Machinability characteristics were measured in terms of tool wear, cutting forces, and machined surface finish quality.

\section{Experimental Procedure}

2.1. Work Materials. Two types of titanium alloys were used in this study; these were wrought grade Ti-6Al-4V and additive manufactured SLM Ti-6Al-4V (selective laser melted). Wrought Ti-6Al-4V was manufactured by hot rolling, followed by postannealing heat treatment at $730^{\circ} \mathrm{C}(2 \mathrm{hrs})$ and
TABLE 1: Chemical composition of the work materials.

\begin{tabular}{lcccccccc}
\hline \multirow{2}{*}{ Materials } & \multicolumn{8}{c}{ Chemical composition (\%) } \\
& $\mathrm{Al}$ & $\mathrm{V}$ & $\mathrm{Fe}$ & $\mathrm{C}$ & $\mathrm{O}$ & $\mathrm{N}$ & $\mathrm{H}$ & $\mathrm{Ti}$ \\
\hline Wrought Ti-6Al-4V & 6.85 & 4.37 & 0.170 & 0.08 & 0.20 & 0.03 & - & $\mathrm{Bal}$ \\
SLM Ti-6Al-4V & 6.82 & 4.20 & 0.325 & 0.08 & 0.34 & 0.05 & 0.015 & $\mathrm{Bal}$ \\
\hline
\end{tabular}

TABLE 2: Mechanical properties of the work materials.

\begin{tabular}{lcccc}
\hline Materials & $\begin{array}{c}\text { Yield } \\
\text { strength } \\
(\mathrm{MPa})\end{array}$ & $\begin{array}{c}\text { Ultimate } \\
\text { tensile } \\
\text { strength } \\
(\mathrm{MPa})\end{array}$ & $\begin{array}{c}\text { Elongation } \\
(\%)\end{array}$ & $\begin{array}{c}\text { Hardness } \\
(\mathrm{HV})\end{array}$ \\
\hline Wrought Ti-6Al-4V & 948 & 994 & 21 & 306 \\
SLM Ti-6Al-4V & 1050 & 1120 & 4 & 360 \\
\hline
\end{tabular}

TABLE 3: Details of the machining test.

\begin{tabular}{lcc}
\hline \multirow{2}{*}{ Cutting conditions } & \multicolumn{2}{c}{ Machining time [24] } \\
& Wrought Ti-6Al-4V & SLM Ti-6Al-4V \\
\hline$V_{c}=60 \mathrm{~m} / \mathrm{min}$ & 378 & 378 \\
$V_{c}=120 \mathrm{~m} / \mathrm{min}$ & 90 & 90 \\
$V_{c}=180 \mathrm{~m} / \mathrm{min}$ & 144 & $16^{*}$ \\
\hline
\end{tabular}

${ }^{*}$ Test was stopped due to high tool wear that resulted in vibrations and drastic increase in cutting forces.

air cooled. SLM Ti-6Al-4V was fabricated using SLM 125 HL machine in an argon atmosphere. Both materials were fabricated in hollow cylinder form. The cylinder dimensions can be viewed in Figure 1. Wrought Ti-6Al-4V had an equiaxed microstructure structure whereas SLM Ti-6Al-4V consisted of a fine acicular microstructure with grain growth in the direction of building. It is found that this acicular microstructure gives rise to high strength and hardness of SLM Ti-6Al-4V over wrought Ti-6Al-4V [9]. The martensite phase present in the acicular microstructure of additive manufactured titanium alloys as a result of rapid heating and cooling due to the nature of the fabrication process gives rise to its higher strength and hardness [11]. The microstructure for both work materials is shown in Figure 2. The chemical composition and the mechanical properties of the work materials used in this research are shown in Tables 1 and 2, respectively.

2.2. Machining Parameters. The machinability of the work materials was tested using face turning method. This machinability test method is specifically designed for testing the machinability of powder metallurgy materials. The machining test method was carried out at three cutting speeds $(\mathrm{mm} / \mathrm{min})$ starting at $V_{c} 60 \mathrm{~m} / \mathrm{min}$, then $120 \mathrm{~m} / \mathrm{min}$, and finally $180 \mathrm{~m} / \mathrm{min}$, with constant feed rate $(f)$ of $0.1 \mathrm{~mm} / \mathrm{rev}$ and depth of cut $(d)$ of $0.5 \mathrm{~mm}$. The details of the machining trials are shown in Table 3. Face turning tests were performed for specific machining time as shown in Table 3. The tests were stopped after these machining passes and the data was recorded. 


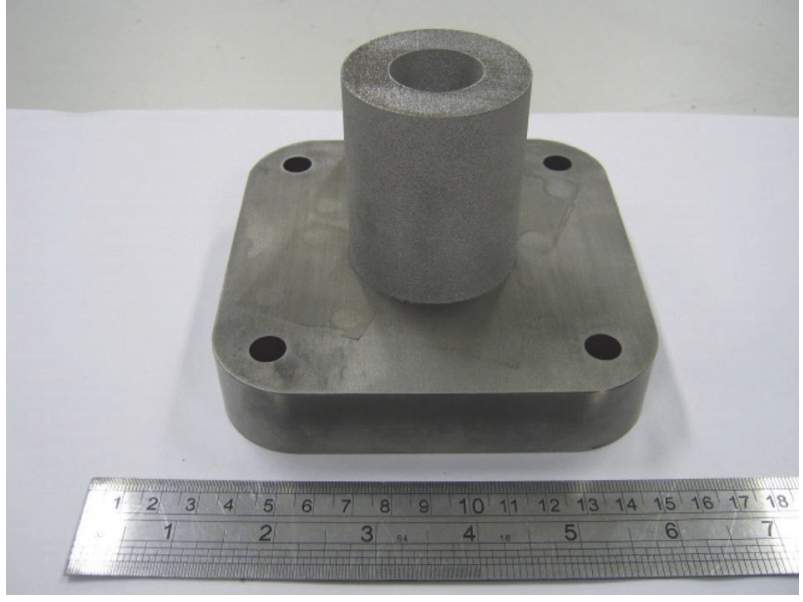

(a)

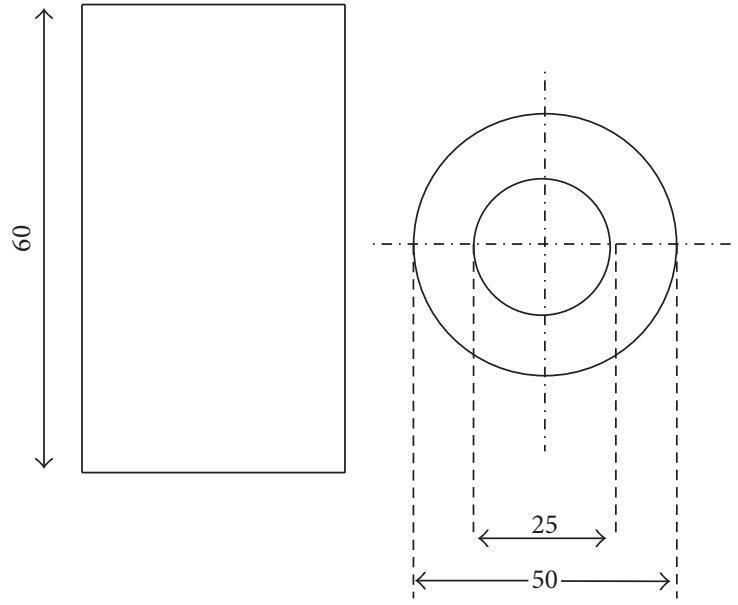

(b)

FIGURE 1: Hollow cylinder fabricated using selective laser melting technology and (b) dimensions of the fabricated hollow cylinder, front and top view.

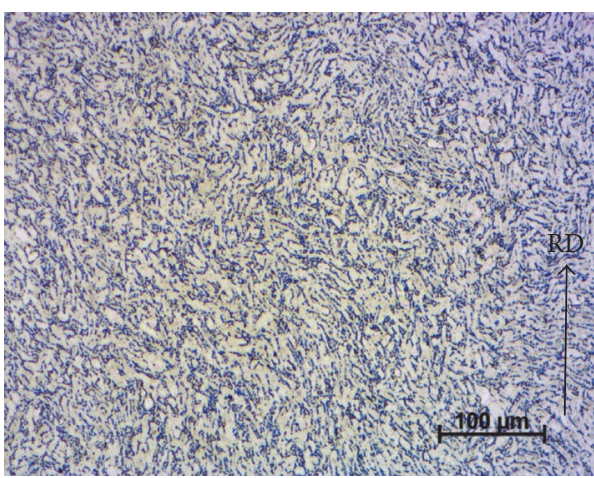

(a)

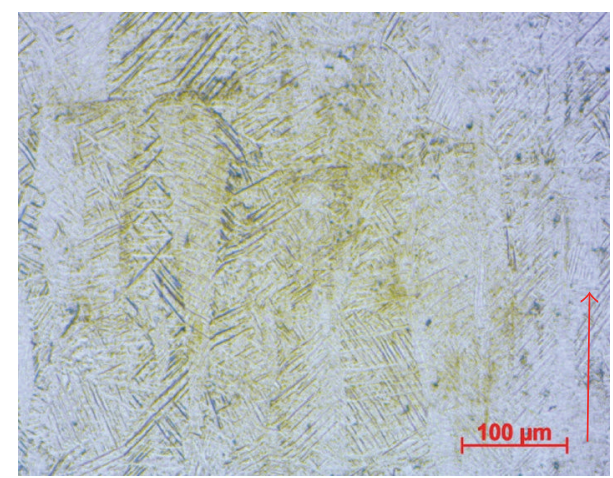

(b)

FIGURE 2: Microstructure of (a) wrought Ti-6Al-4V and (b) SLM Ti-6Al-4V (arrow mark indicates the direction of building).

These conditions are specifically used for finish machining applications. Face turning tests were performed on Nakamura-Tome AS-200 machining center using a double sided $55^{\circ}$ rhombic cutting tool insert with positive rake angle supplied by ISCAR. The tool was PVD coated with TiAlN + TiN coating layer.

2.3. Machinability Test Details. Cutting forces were measured in each test using a Kistler 9119AA2 dynamometer attached to the cutting tool as shown in Figure 3. The dynamometer was connected to a Kistler 5070 multichannel charge amplifier. Tool wear and wear mechanisms were studied using an optical and scanning electron microscope. Surface roughness of the machined surface was measured using an Alicona Infinite Focus 3D optical surface profilometer. Three readings were taken at different locations and the mean of these values was recorded. Secondary electron images of the machined surface were captured using a Joel made JSM-IT300LV versatile research scanning electron microscope to study the machined surface characteristics.

\section{Results and Discussions}

Machining trials found selective laser melted titanium alloy SLM Ti-6Al-4V machined with higher tool wear, cutting forces, and machine surface roughness compared to wrought Ti-6Al-4V. This difference in machinability characteristics of these materials can be attributed to the higher strength and hardness of SLM Ti-6Al-4V over wrought material due to its peculiar acicular microstructure.

3.1. Tool Wear. Macroscopic images of the worn cutting tool and the graph illustrating maximum flank wear after machining wrought and SLM Ti-6A-4V at various spindle speeds are shown in Figures 4 and 5. It can be seen from the figures that higher wear was observed in the cutting tools that machined SLM Ti-6Al-4V. At cutting speeds of 60 and $120 \mathrm{~m} / \mathrm{min}$, there was less difference in wear for machining these materials whereas, at $180 \mathrm{~m} / \mathrm{min}$, huge difference in wear was observed. Maximum flank wear was found to be highest for tool used in machining SLM Ti-6Al-4V at $180 \mathrm{~m} / \mathrm{min}$. Therefore, it can 


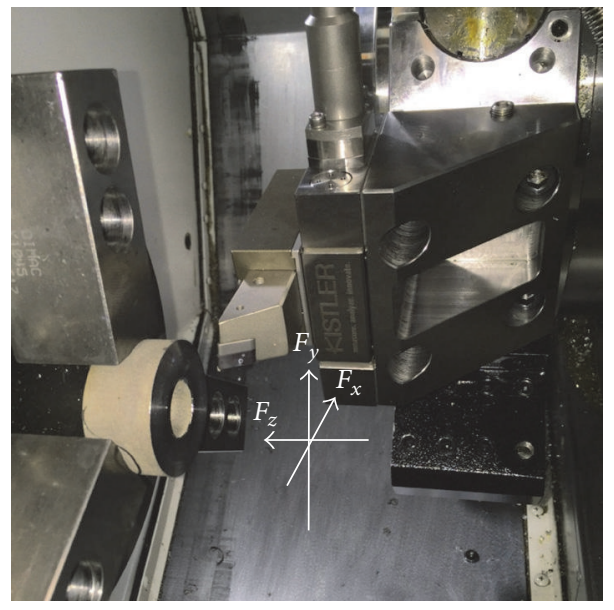

Figure 3: Experimental setup for the machining test.


FIGURE 4: Macroscopic images of rake face and flank face of the cutting tool after machining wrought and SLM Ti-6Al-4V at different cutting speeds. 


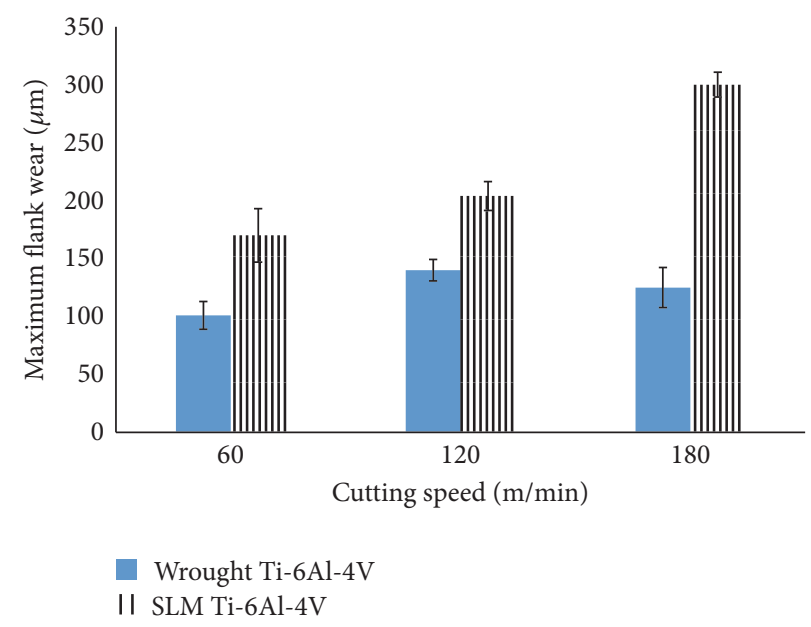

FIGURE 5: Maximum flank wear during machining of wrought and SLM Ti-6Al-4V.

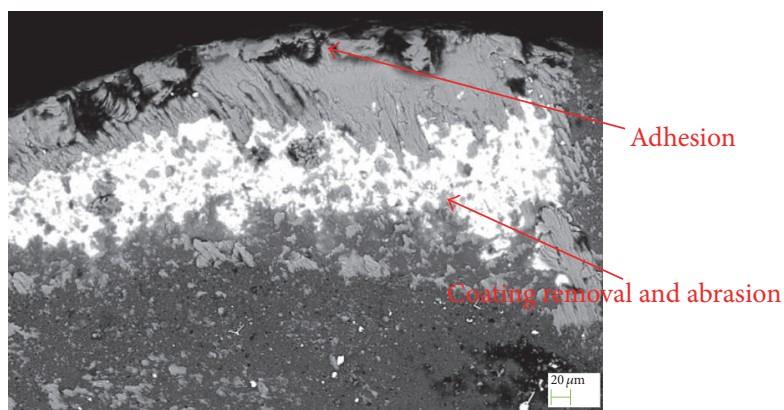

(a)

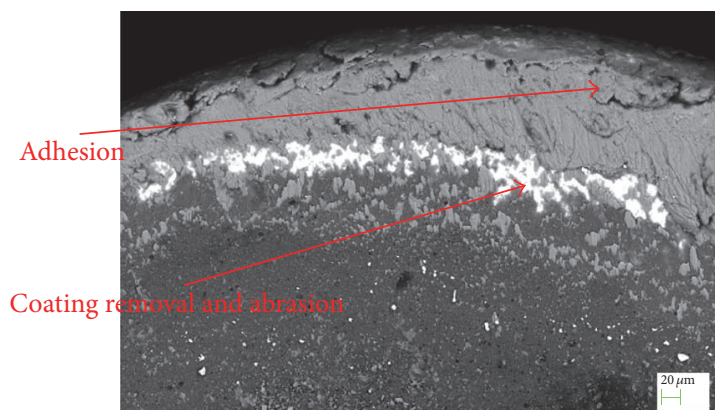

(b)

FIGURE 6: SEM image of cutting tool after machining (a) wrought and (b) SLM Ti- $6 \mathrm{Al}-4 \mathrm{~V}$ at $V_{c}=180 \mathrm{~m} / \mathrm{min} ; f=0.1 \mathrm{~mm} / \mathrm{rev}$; and $d=0.5 \mathrm{~mm}$ for 378 seconds.

be concluded that high cutting speeds result in rapid wear of the cutting tool during machining of SLM Ti-6Al-4V. This catastrophic failure of the cutting tools at high cutting speeds is possibly due to the high temperature and poor thermal conductivity of titanium alloy that accelerates tool wear.

3.2. Tool Wear Mechanisms. Wear mechanisms in machining both the materials were found to be quite similar at speeds of 60 and $120 \mathrm{~m} / \mathrm{min}$. Examination of the cutting tools used in these machining conditions revealed that coating delamination, adhesion, and abrasion are the major wear mechanisms in the cutting tool, shown in Figure 6. Coating delamination in coated carbide tools during machining of titanium alloys is more frequently observed by various authors [25-27]. This wear is attributed to the chemical reaction and crack propagation at the substrate interface [28]. The exposure of the tool materials due to coating delamination increased the susceptibility of dissolution/diffusion which eventually leads to gradual removal of tool materials. Adhesion of work material on the cutting tool was observed for almost all cutting conditions due to the poor thermal conductivity and high chemical reactivity of titanium alloys. Adhesion and diffusion are found to be the major wear mechanism in machining titanium alloys and often lead to crater wear, weakening of the cutting edge, and tearing of the tool particles [29]. Abrasion wear was found to be the major cause of flank wear at low cutting speeds. At a cutting speed of $180 \mathrm{~m} / \mathrm{min}$, severe chipping and attrition were found to be the major tool wear mechanism in machining SLM Ti-6Al-4V unlike wrought Ti-6Al-4V. Chipping and attrition observed in the cutting tool reveal that the tool is subjected to high mechanical and thermal stresses that occur during machining of SLM Ti-6Al-4V at high cutting speeds. The chipped off cutting edge and the weakened tool particles in the cutting tool after machining SLM Ti-6Al-4V at high cutting speeds are shown in Figure 7.

3.3. Cutting Forces. Figures 8(a), 8(b), and 8(c) show the measured average cutting force of all experimental trials from start to finish. Cutting forces correlated well with the mechanical strength and hardness of the material. It is well established that higher cutting forces are generated when machining materials of higher strength and hardness, which explains the recorded cutting forces for SLM Ti-6Al-4V being higher. Arrazola et al. [30] also found a correlation between the cutting forces and materials properties during machining of titanium alloys. SLM Ti-6Al-4V with higher strength and hardness required more forces for cutting than 

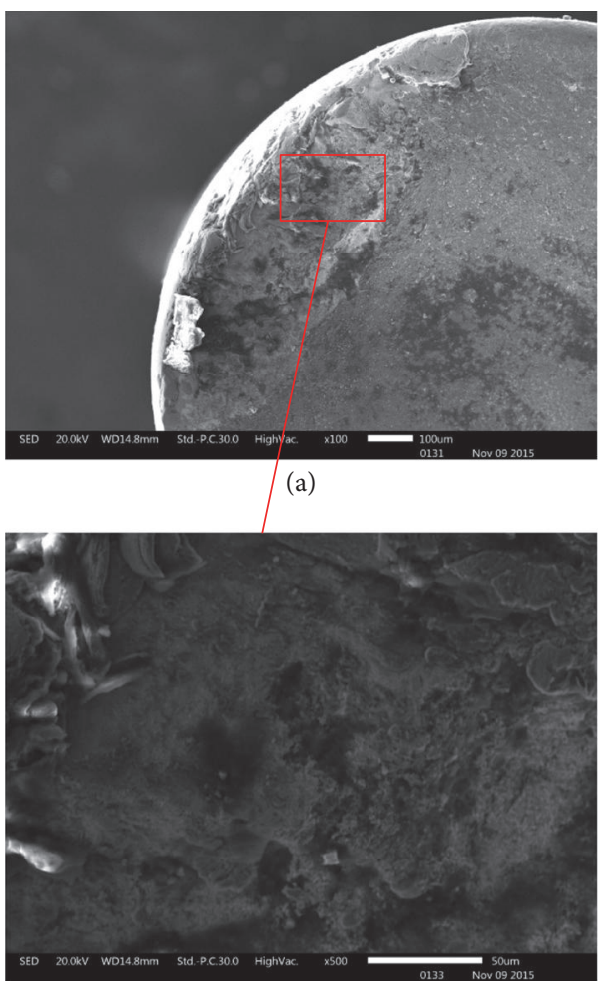

(b)

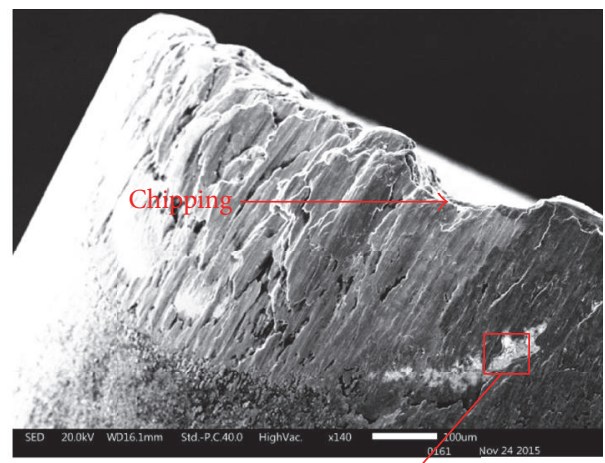

(c)

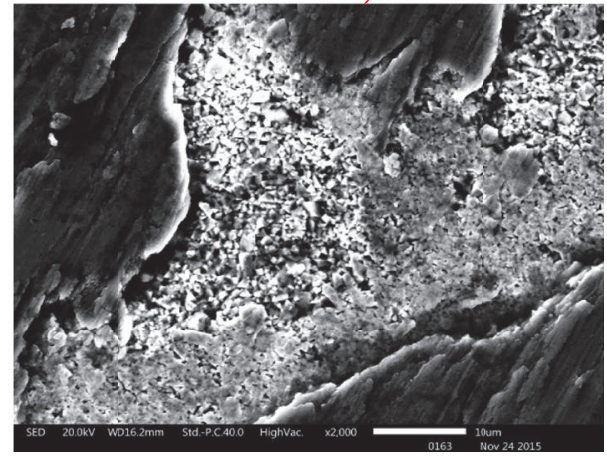

(d)

FIGURE 7: SEM image of the cutting tool after machining SLM Ti-6Al-4V for 16 seconds at $V_{c}=180 \mathrm{~m} / \mathrm{min} ; f=0.1 \mathrm{~mm} / \mathrm{rev}$; and $d=0.5 \mathrm{~mm}$ : (a) rake face of the cutting tool, (b) higher magnification image of the rake face showing crater and weakened tool particles, (c) flank face of the cutting tool illustrating chipping of the cutting edge, and (d) higher magnification image illustrating the attrition wear mechanism.

wrought Ti-6Al-4V. At $60 \mathrm{~m} / \mathrm{min}$, the cutting forces were not affected due to wear. The cutting forces increased slightly during machining at $120 \mathrm{~m} / \mathrm{min}$ for both the materials. But, at $180 \mathrm{~m} / \mathrm{min}$, there was a significant increase in cutting forces during machining of SLM Ti-6Al-4V. The probable cause was found due to concentrated large tool wear on the flank face of the insert.

3.4. Surface Roughness. The measured surface roughness $R_{a}$ of the machined work piece and the Alicona scan images illustrating the 3D topography of the machined surface at different cutting speeds are shown in Figures 9 and 11, respectively. The graph showed that surface roughness in both wrought and SLM Ti-6Al-4V reduced with increasing cutting speed, leading to improved surface quality. The improvement in surface quality is also evident in SEM images of the machined surfaces displayed in Figure 10.

At low cutting speed, the measured surface roughness for both work piece materials was found similar, measuring high roughness $R_{a}$. With the increase in the cutting speed, the surface quality of both wrought and SLM Ti-6Al-4V improved reducing the $R_{a}$ value. The best surface quality was observed at high cutting of $180 \mathrm{~m} / \mathrm{min}$. Good surface finish was observed even for high tool wear illustrating that tool wear did not affect the surface quality adversely. SEM image of the machined surface illustrates that deep tool indentation and adhered chip materials are quite severe in the wrought specimens as compared to the SLM specimens (as shown in Figure 10). This might be possibly due to the difference in the material properties. However at high speeds the SLM machined surface exhibited severe surface smearing due to the high tool wear which is evident from the SEM and 3D topography images of the machined surface in Figures 10 and 11 , respectively.

\section{Conclusions}

Face turning tests were performed on wrought and additive manufactured Ti-6Al-4V using PVD coated carbide tools. Machinability of these two differently processed materials was studied and compared for different speeds. Machinability was characterized in terms of tool wear, cutting forces, and surface roughness. Based on Results and Discussions, the following conclusions can be made:

(i) Maximum flank wear was found to be higher during machining of SLM Ti-6Al-4V compared to wrought Ti-6Al-4V for all cutting speeds employed.

(ii) The flank wear increased rapidly at high machining speeds and led to catastrophic failure of the cutting tool during machining of SLM Ti-6Al-4V.

(iii) Coating delamination, adhesion, abrasion, attrition, and chipping were found to be the dominant tool wear mechanisms during machining of SLM Ti-6Al-4V. 


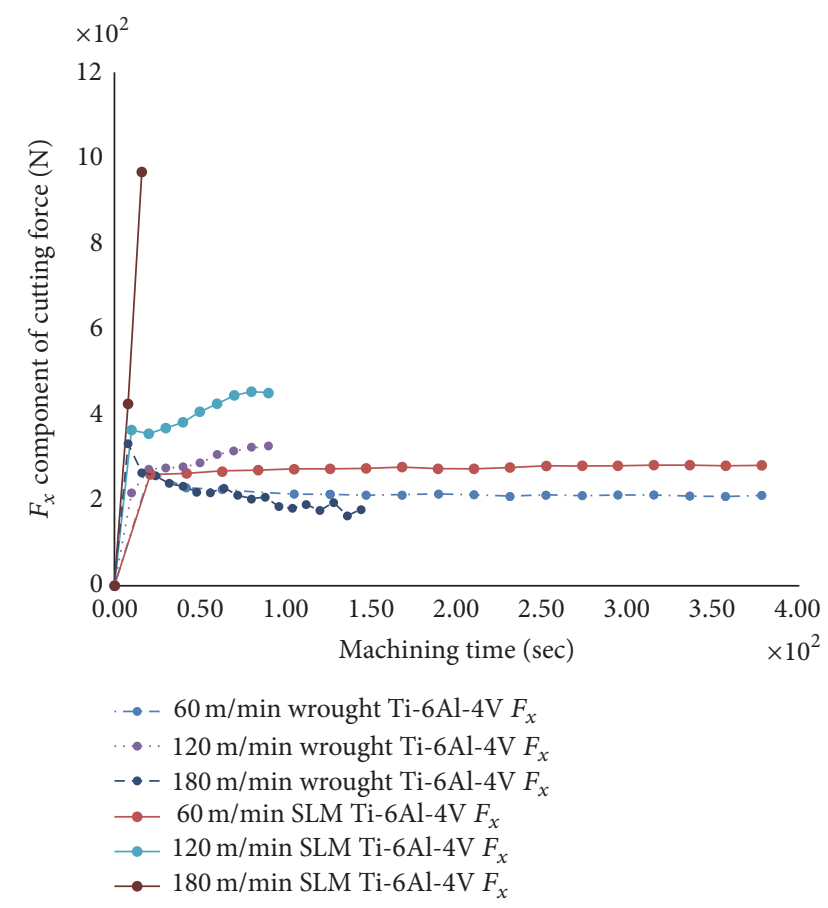

(a)

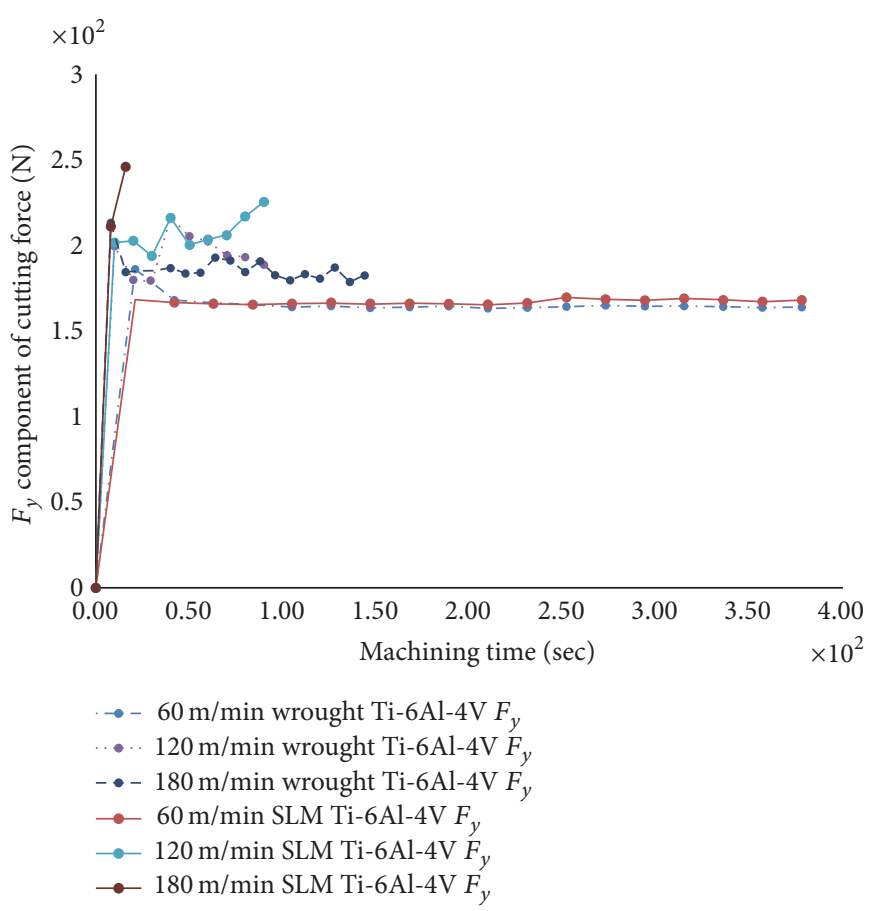

(b)



(c)

FIgure 8: ( $a, b$, and c) Different components of cutting forces during machining of wrought and SLM Ti-6Al-4V.

(iv) Cutting forces are found to be higher during machining of SLM Ti-6Al-4V due to its high strength and hardness as compared to wrought $\mathrm{Ti}-6 \mathrm{Al}-4 \mathrm{~V}$.

(v) Surface roughness $\left(R_{a}\right)$ decreased with increase in cutting speed during machining of both the materials, despite the high tool wear observed. SEM images of the machined surface reveal that the surface becomes smoother with cutting speeds.

\section{Competing Interests}

The authors declare that there is no conflict of interests regarding the publication this article. 


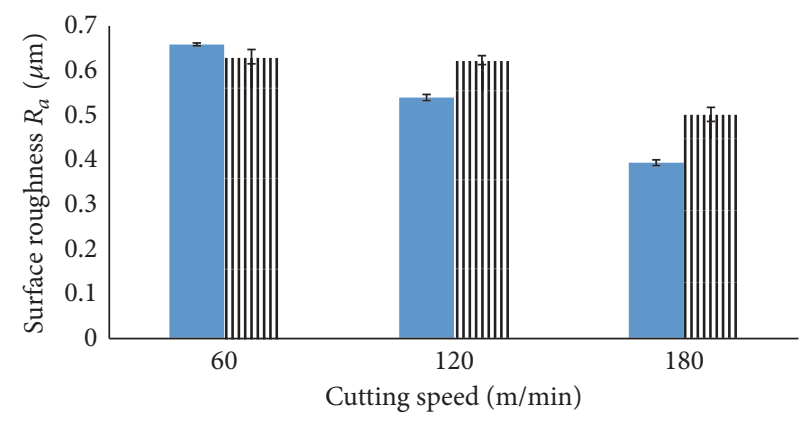

Wrought Ti-6Al-4V

II SLM Ti-6Al-4V

FIGURE 9: Variation of surface roughness with speeds in machining of wrought and SLM Ti-6Al-4V.

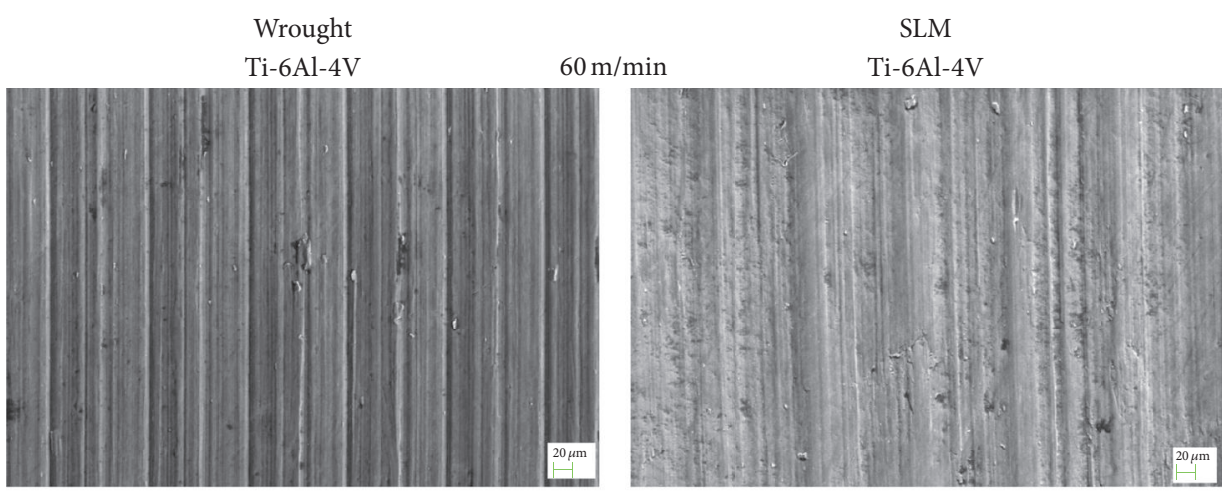

$120 \mathrm{~m} / \mathrm{min}$
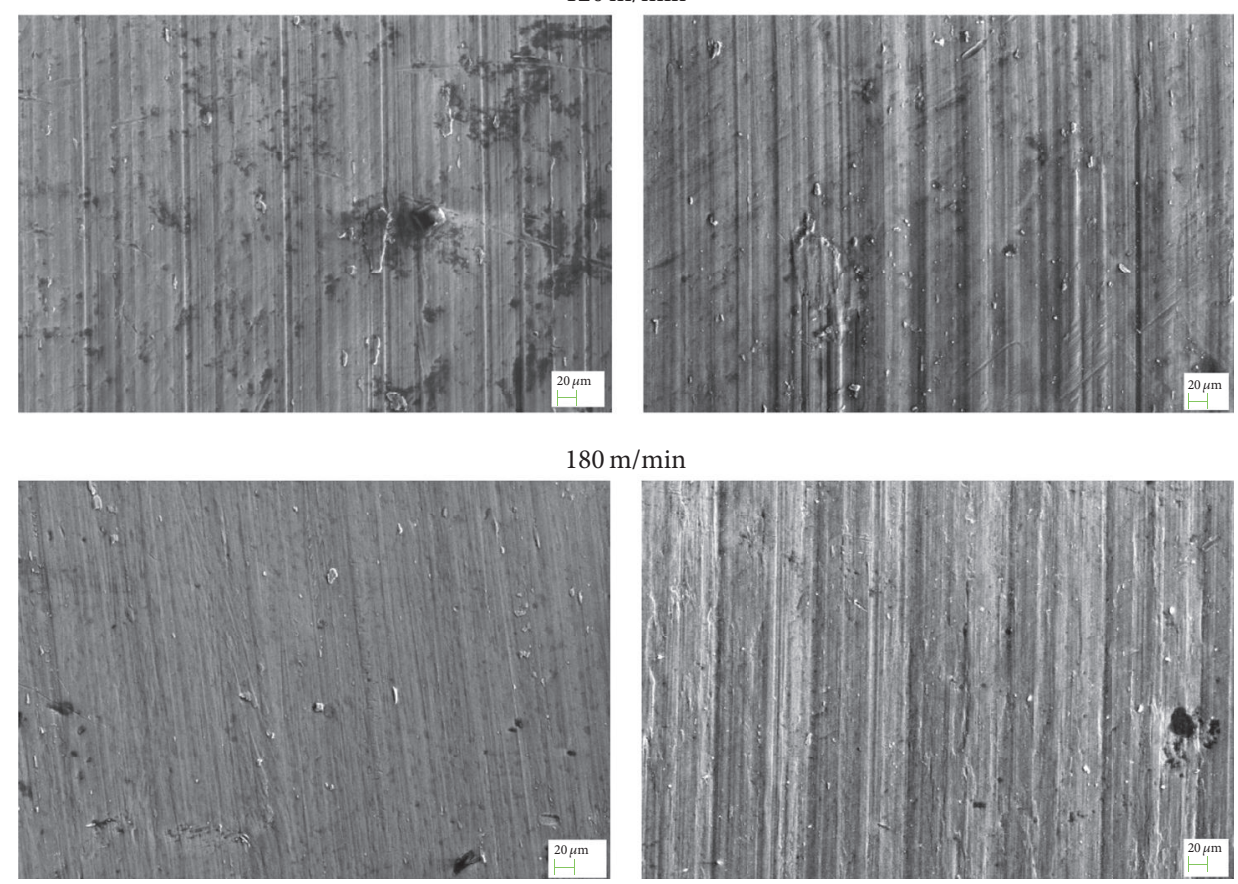

FIGURE 10: SEM image of the machined surface of wrought Ti-6Al-4V and SLM Ti-6Al-4V. 

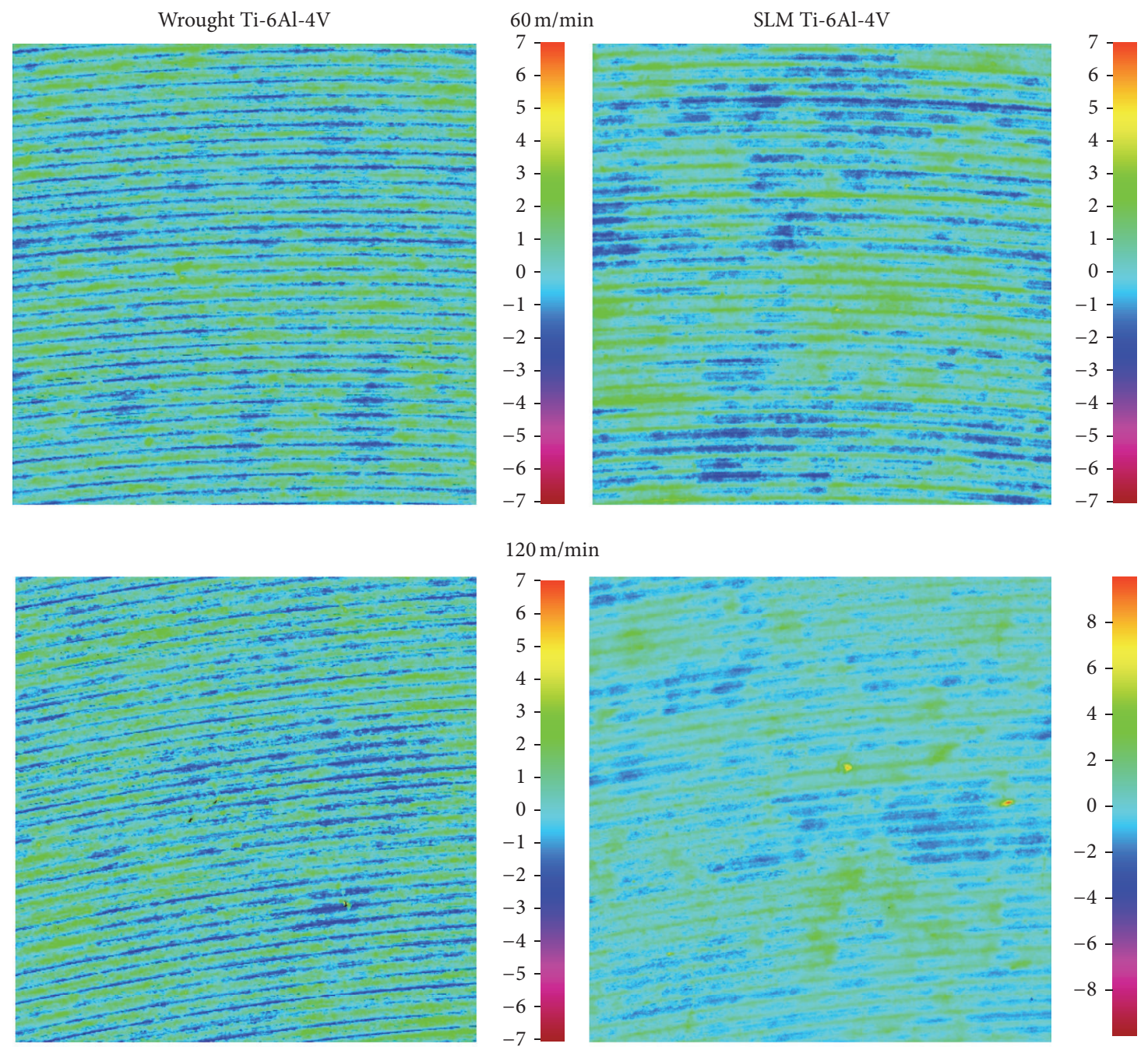

$120 \mathrm{~m} / \mathrm{min}$
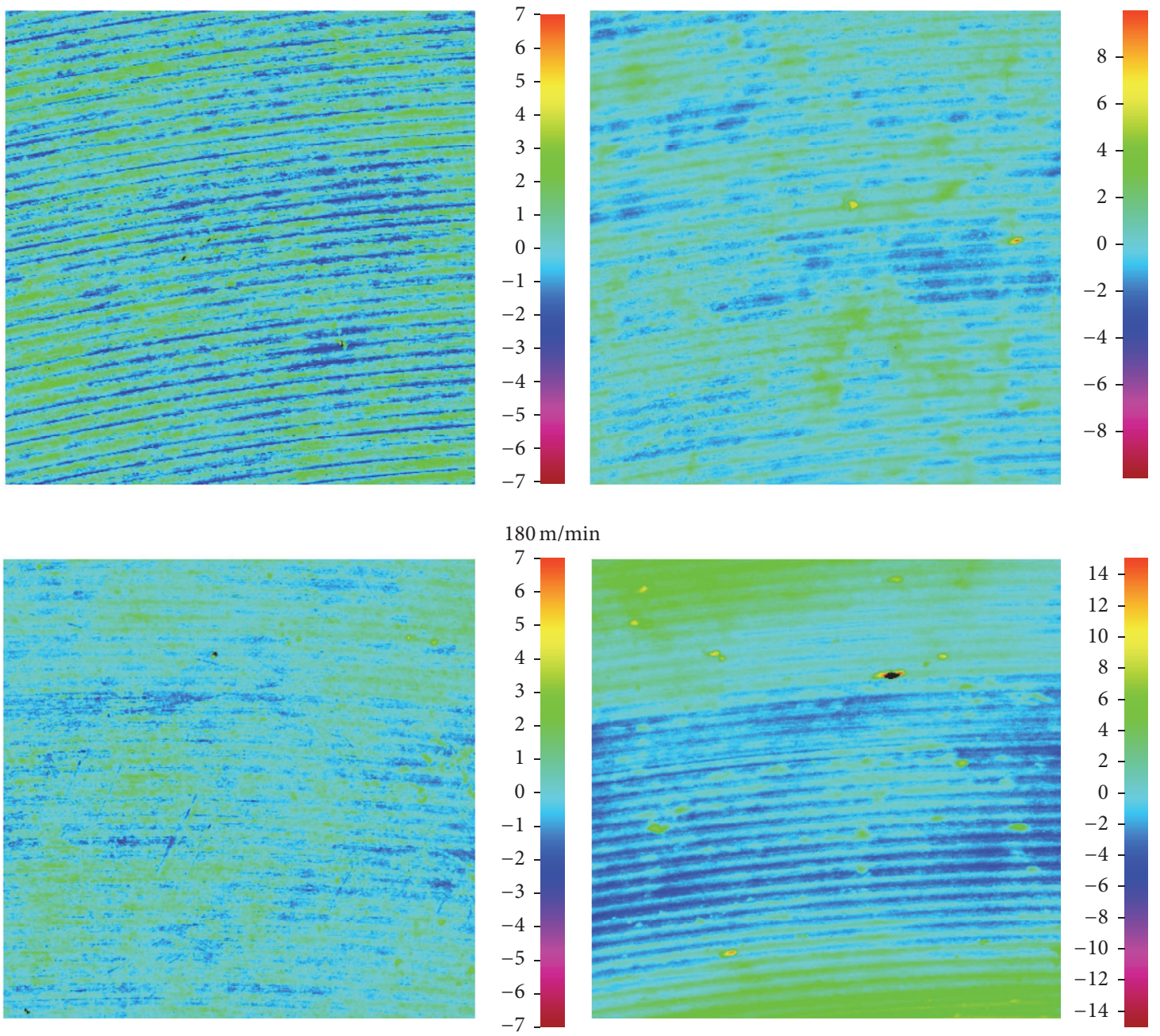

FIGURE 11: Alicona scan images illustrating the 3D topography of the machined surface. 


\section{Acknowledgments}

The authors would like to acknowledge the help and support of Bharat Forge, India, and Kalyani Center for Technology and Innovation, India, in this project. The authors would also like to specially thank Dr. Raj Kumar Singh, Senior Director of Kalyani Center for Technology and Innovation, India, for his valuable help, support, encouragement, and discussions for this project.

\section{References}

[1] C. Leyens and M. Peters, Titanium and Titanium Alloys: Fundamentals and Applications, John Wiley \& Sons, New York, NY, USA, 2003.

[2] J. D. Paramore, Z. Z. Fang, P. Sun, M. Koopman, K. S. R. Chandran, and M. Dunstan, "A powder metallurgy method for manufacturing Ti-6Al-4V with wrought-like microstructures and mechanical properties via hydrogen sintering and phase transformation (HSPT)," Scripta Materialia, vol. 107, pp. 103-106, 2015.

[3] S. H. Huang, P. Liu, A. Mokasdar, and L. Hou, "Additive manufacturing and its societal impact: a literature review," International Journal of Advanced Manufacturing Technology, vol. 67, no. 5-8, pp. 1191-1203, 2013.

[4] S. Leuders, M. Thöne, A. Riemer et al., "On the mechanical behaviour of titanium alloy TiAl6V4 manufactured by selective laser melting: fatigue resistance and crack growth performance," International Journal of Fatigue, vol. 48, pp. 300-307, 2013.

[5] W. E. Frazier, "Metal additive manufacturing: a review," Journal of Materials Engineering and Performance, vol. 23, no. 6, pp. 1917-1928, 2014.

[6] G. N. Levy, R. Schindel, and J. P. Kruth, "Rapid manufacturing and rapid tooling with layer manufacturing (LM) technologies, state of the art and future perspectives," CIRP AnnalsManufacturing Technology, vol. 52, no. 2, pp. 589-609, 2003.

[7] M. Wehmöller, P. H. Warnke, C. Zilian, and H. Eufinger, "Implant design and production-a new approach by selective laser melting," International Congress Series, vol. 1281, pp. 690-695, 2005.

[8] N. Hopkinson, R. Hague, and P. Dickens, Rapid Manufacturing: an Industrial Revolution for the Digital Age, John Wiley \& Sons, New York, NY, USA, 2006.

[9] M. Shunmugavel, A. Polishetty, and G. Littlefair, "Microstructure and mechanical properties of wrought and additive manufactured Ti-6Al-4V cylindrical bars," Procedia Technology, vol. 20, pp. 231-236, 2015.

[10] L. E. Murr, E. V. Esquivel, S. A. Quinones et al., "Microstructures and mechanical properties of electron beam-rapid manufactured $\mathrm{Ti}-6 \mathrm{Al}-4 \mathrm{~V}$ biomedical prototypes compared to wrought Ti-6Al-4V," Materials Characterization, vol. 60, no. 2, pp. 96-105, 2009.

[11] L. E. Murr, S. A. Quinones, S. M. Gaytan et al., "Microstructure and mechanical behavior of $\mathrm{Ti}-6 \mathrm{Al}-4 \mathrm{~V}$ produced by rapidlayer manufacturing, for biomedical applications," Journal of the Mechanical Behavior of Biomedical Materials, vol. 2, no. 1, pp. 20-32, 2009.

[12] K. Osakada and M. Shiomi, "Flexible manufacturing of metallic products by selective laser melting of powder," International Journal of Machine Tools and Manufacture, vol. 46, no. 11, pp. 1188-1193, 2006.
[13] E. O. Ezugwu, J. Bonney, and Y. Yamane, "An overview of the machinability of aeroengine alloys," Journal of Materials Processing Technology, vol. 134, no. 2, pp. 233-253, 2003.

[14] E. O. Ezugwu and Z. M. Wang, "Titanium alloys and their machinability-a review," Journal of Materials Processing Technology, vol. 68, no. 3, pp. 262-274, 1997.

[15] X. Yang and C. R. Liu, "Machining titanium and its alloys," Machining Science and Technology, vol. 3, no. 1, pp.107-139, 1999.

[16] O. Oyelola, P. Crawforth, R. M'Saoubi, and A. T. Clare, "Machining of additively manufactured parts: implications for surface integrity," Procedia CIRP, vol. 45, pp. 119-122, 2016.

[17] F. Montevecchi, N. Grossi, H. Takagi, A. Scippa, H. Sasahara, and G. Campatelli, "Cutting forces analysis in additive manufactured AISI H13 alloy," Procedia CIRP, vol. 46, pp. 476-479, 2016.

[18] S. Bruschi, G. Tristo, Z. Rysava, P. Bariani, D. Umbrello, and L. De Chiffre, "Environmentally clean micromilling of electron beam melted Ti6Al4V," Journal of Cleaner Production, vol. 133, pp. 932-941, 2016.

[19] E. Brinksmeier, G. Levy, D. Meyer, and A. B. Spierings, "Surface integrity of selective-laser-melted components," CIRP AnnalsManufacturing Technology, vol. 59, no. 1, pp. 601-606, 2010.

[20] A. Bordin, S. Bruschi, A. Ghiotti, F. Bucciotti, and L. Facchini, "Comparison between wrought and EBM Ti6Al4V machinability characteristics," Key Engineering Materials, vol. 611-612, pp. 1186-1193, 2014.

[21] A. Bordin, S. Bruschi, A. Ghiotti, and P. F. Bariani, "Analysis of tool wear in cryogenic machining of additive manufactured Ti6Al4V alloy," Wear, vol. 328-329, pp. 89-99, 2015.

[22] M. S. A. Aziz, T. Ueda, T. Furumoto, S. Abe, A. Hosokawa, and A. Yassin, "Study on machinability of laser sintered materials fabricated by layered manufacturing system: influence of different hardness of sintered materials," Procedia CIRP, vol. 4, pp. 79-83, 2012.

[23] D. Mori, Ed., Additive Manufacturing in Milling Quality, 2014.

[24] J. A. Arsecularatne, L. C. Zhang, and C. Montross, "Wear and tool life of tungsten carbide, PCBN and PCD cutting tools," International Journal of Machine Tools and Manufacture, vol. 46, no. 5, pp. 482-491, 2006.

[25] M. Nouari and A. Ginting, "Wear characteristics and performance of multi-layer CVD-coated alloyed carbide tool in dry end milling of titanium alloy," Surface and Coatings Technology, vol. 200, no. 18-19, pp. 5663-5676, 2006.

[26] M. Nouari and H. Makich, "Experimental investigation on the effect of the material microstructure on tool wear when machining hard titanium alloys: Ti-6Al-4V and Ti-555," International Journal of Refractory Metals and Hard Materials, vol. 41, pp. 259-269, 2013.

[27] S. H. I. Jaffery and P. T. Mativenga, "Wear mechanisms analysis for turning Ti-6Al-4V-towards the development of suitable tool coatings," The International Journal of Advanced Manufacturing Technology, vol. 58, no. 5-8, pp. 479-493, 2012.

[28] A. Jawaid, S. Sharif, and S. Koksal, "Evaluation of wear mechanisms of coated carbide tools when face milling titanium alloy," Journal of Materials Processing Technology, vol. 99, no. 1-3, pp. 266-274, 2000.

[29] W. Min, W. Min, and Z. Youzhen, "Diffusion wear in milling titanium alloys," Materials Science and Technology, vol. 4, no. 6, pp. 548-553, 1988.

[30] P.-J. Arrazola, A. Garay, L.-M. Iriarte, M. Armendia, S. Marya, and F. Le Maître, "Machinability of titanium alloys (Ti6Al4V and Ti555.3)," Journal of Materials Processing Technology, vol. 209, no. 5, pp. 2223-2230, 2009. 

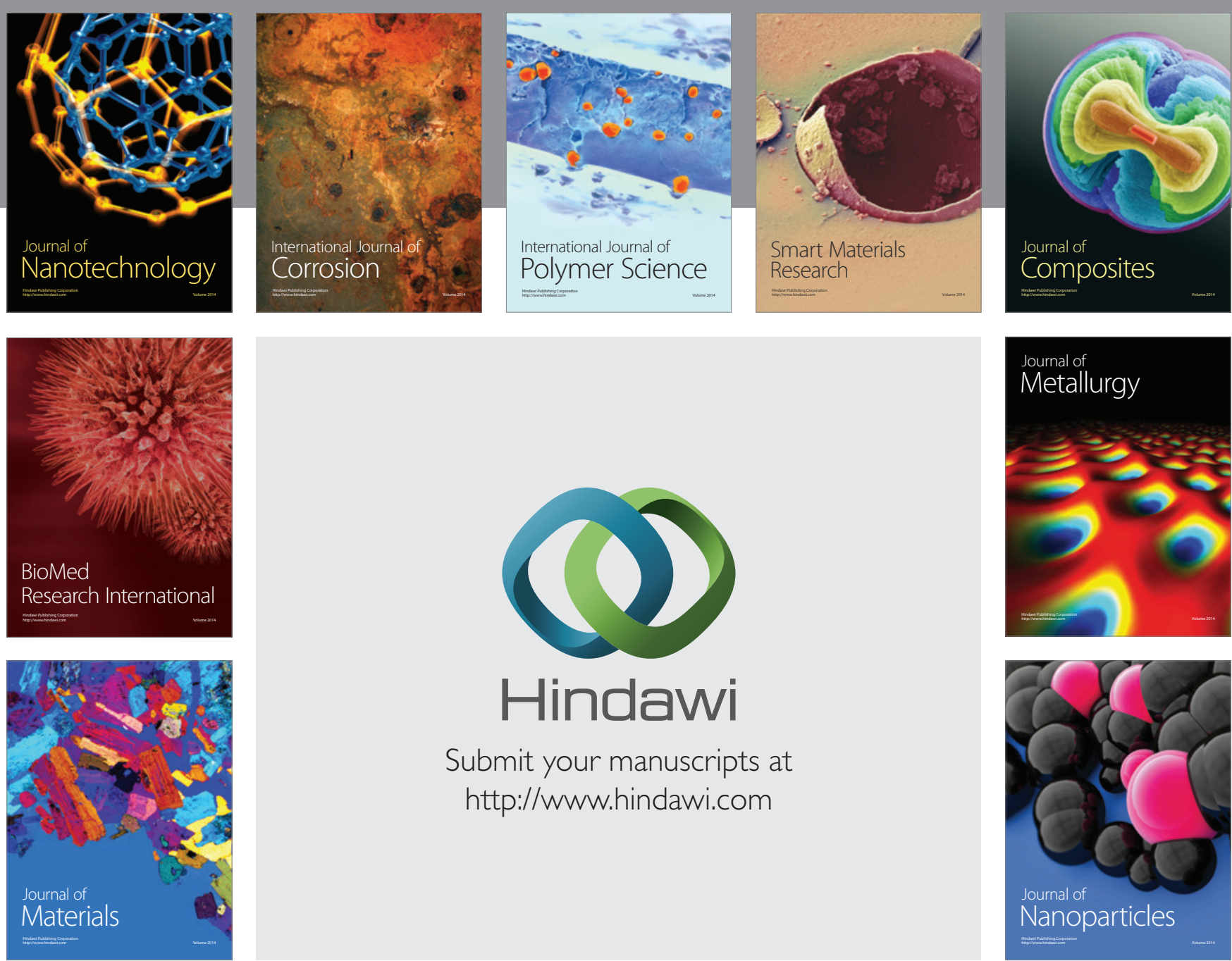

\section{Hindawi}

Submit your manuscripts at

http://www.hindawi.com

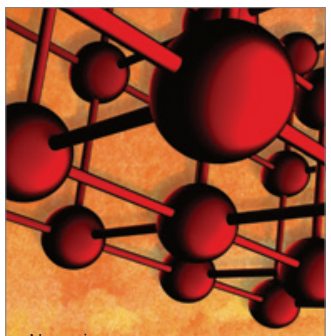

Materials Science and Engineering
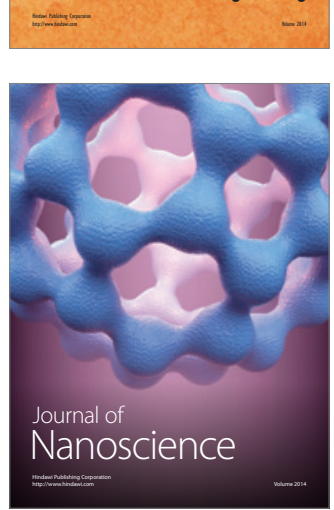

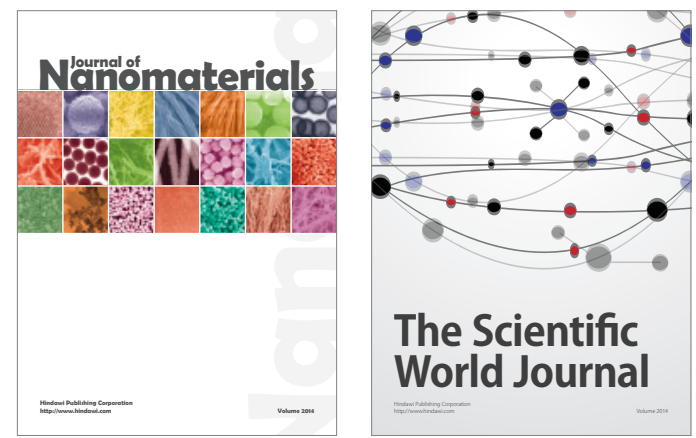

The Scientific World Journal
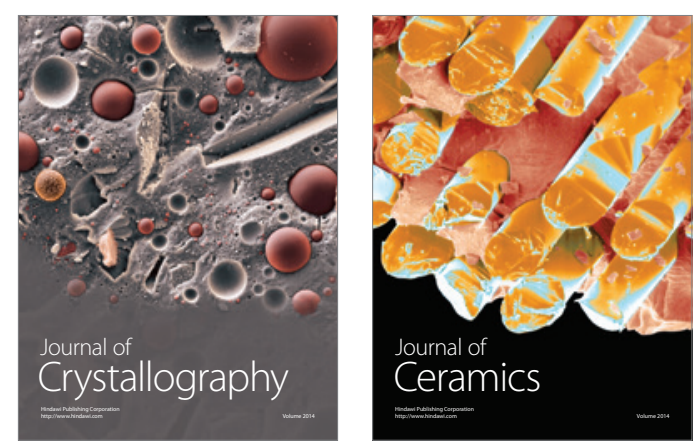
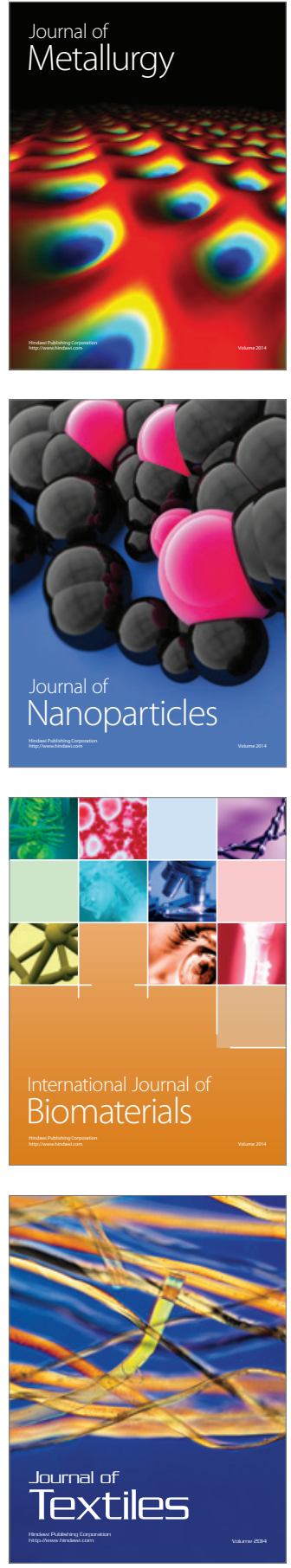